\title{
CÂMARAS CLIMÁTICAS PARA O ENVELHECIMENTO ACELERADO: AÇÃO DE MICROAMBIENTES SOBRE BENS CULTURAIS
}

\author{
Renato Inhasz Paiva, José Roberto Caetano da Rocha e Andrea Cavicchioli* \\ Escola de Artes, Ciências e Humanidades, Universidade de São Paulo, Av. Arlindo Bettio, 1000, 03828-000 São Paulo - SP, Brasil \\ Fernando Silva Lopes e Dalva Lúcia Araújo de Faria \\ Instituto de Química, Universidade de São Paulo, Av. Prof. Lineu Prestes, 748, 05508-000 São Paulo - SP, Brasil
}

Recebido em 31/8/08; aceito em 15/6/09; publicado na web em 27/11/09

\begin{abstract}
ENVIRONMENTAL CHAMBERS FOR THE ACCELERATED AGEING: EFFECT OF MICROCLIMATES ON CULTURAL HERITAGE. Environmental chambers were designed for the accelerated ageing of materials used in artistic artifacts to study the synergistic action of temperature, humidity, UV and visible radiation and gaseous pollutants. Two inox-steel/PTFE compartments are kept under controlled temperature and relative humidity, whose values are transmitted to a PC, which stores, plots in real time and continuously feedback heating and humidifying devices through logical signals. A borosilicate, or quartz, window allows the irradiation inside the chamber from an external source. A flow of purified air purges the chamber and conveys selected pollutants from an external source. Each independent compartment works under either stationary or cyclic conditions.
\end{abstract}

Keywords: accelerated ageing; environmental chambers; cultural heritage.

\section{INTRODUÇÃO}

A preocupação com a conservação de patrimônio cultural, apesar de relativamente recente, vem experimentando no Brasil um crescimento muito expressivo, ultrapassando os limites da comunidade de conservadores e restauradores e atraindo cada vez mais a atenção de pesquisadores de outras áreas, especificamente os das chamadas hard sciences. Um aspecto particularmente importante nesse contexto é aquele relacionado com a degradação de materiais, uma vez que a compreensão dos mecanismos responsáveis por tais processos é essencial na determinação dos procedimentos a serem adotados na preservação de bens culturais.

Todos os materiais têm uma tendência mais ou menos acentuada a sofrerem degeneração com o passar do tempo. Este problema, por estar ligado à durabilidade e ao tempo de vida útil de materiais usados na manufatura de bens de consumo, geralmente tem fortes implicações econômicas, comerciais e de segurança, despertando o máximo interesse no setor produtivo e, por reflexo, na comunidade científica. Evidentemente, as obras de arte também são sujeitas à degradação, no entanto, apresentam a peculiaridade de serem objetos únicos, preciosos, vulneráveis, muitas vezes já parcialmente deteriorados e para os quais ainda se almeja um longo tempo de vida. ${ }^{1-4}$

A natureza e a rapidez do decaimento dos materiais são inevitavelmente afetadas pelo nível de estresse infligido por fatores ambientais, tais como calor, umidade, radiação luminosa e poluentes gasosos, como enfatizado especialmente por Thomson, ${ }^{1}$ Mills e White ${ }^{5}$ e Feller. ${ }^{6}$ Em particular, uma preocupação mais específica para com os efeitos de poluentes gasosos sobre obras de arte em ambientes internos começou a se difundir durante os anos $80,{ }^{7}$ impondo-se definitivamente como tópico de investigação para os profissionais da área de conservação no começo da década de $1990 .{ }^{3}$ Contudo, as investigações, geralmente focadas em materiais como tintas, vernizes, pigmentos, corantes, papel e metais, quase sempre enfatizam um único fator de agressão, muitas vezes a radiação luminosa (ao menos no caso de materiais orgânicos), desconsiderando a contribuição sinérgica dos outros fatores, apesar desta ser reconhecida como um aspecto impor-

*e-mail: andrecav@usp.br tante a ser levado em conta nos processos degradativos. ${ }^{8,9}$ Estabelecer as complexas interações entre os materiais e seus componentes de um lado e os vários agentes de risco ambiental externos do outro é tarefa objetivamente árdua, inclusive pela falta de equipamentos que permitam expor de forma simultânea e controlada os materiais aos diversos fatores ambientais.

Neste trabalho apresenta-se o projeto, a construção e o funcionamento de um sistema de câmaras climáticas desenvolvido para induzir o envelhecimento acelerado de materiais alvo do estudo sob o controle de quatro fatores ambientais que influenciam as transformações físico-químicas: radiação luminosa (luz), temperatura (T), umidade relativa (UR) e composição do ar (AR). A idéia de implementar este dispositivo surgiu em nosso grupo de pesquisa quando do desenvolvimento de dosímetros piezelétricos concebidos para obter informações sobre o impacto global de determinados microambientes sobre os processos de degradação de materiais pictóricos. ${ }^{10,11} \mathrm{O}$ uso de sensores deste tipo (que recentemente começaram a ser denominados de Impact Sensors) permite estabelecer o grau de risco de danos aos bens culturais e foi recentemente discutido por Bacci et al.. ${ }^{12}$

Câmaras de envelhecimento acelerado estão efetivamente disponíveis no mercado, porém a um custo bastante elevado e sem a versatilidade de funcionamento exigida por estudos da ação sinérgica de tais fatores ambientais. Por exemplo, muitas câmaras comerciais utilizam exclusivamente a radiação luminosa como fator de envelhecimento artificial, proporcionando geralmente um controle satisfatório da temperatura, mas pouco efetivo da umidade relativa. Sistemas pré-existentes dificilmente oferecem como opção a possibilidade de funcionar em ciclos de diferentes níveis de estresse aplicado, por exemplo, T e UR baixas e altas ou com e sem iluminação. Cabe salientar, também, que equipamentos comerciais são geralmente destinados a ensaios de intemperismo para avaliar a estabilidade e a durabilidade dos materiais em condições desnecessariamente drásticas, que não condizem com as condições ambientais relativamente brandas às quais os bens culturais, abrigados via de regra em espaços internos (indoor environments) como museus, galerias e prédios históricos, estão sujeitos.

Com artefatos desta natureza o que interessa não é tanto realizar uma previsão de seu tempo de vida útil, o que implica em esforços de extrapolação dos resultados de testes acelerados para situações 
reais, e sim evidenciar quais fatores são determinantes na preservação dos materiais visando manter sua integridade e prolongá-la no tempo. Esta diferença de objetivos faz com que para investigações sobre materiais do patrimônio cultural não seja necessário infligir um grau de aceleração muito elevado, como aquele normalmente proporcionado por equipamentos comerciais. Por outro lado, deve-se buscar entender de que maneira os diversos fatores interagem entre si (sinergismo) na degradação dos materiais, de onde a necessidade de dispor de dispositivos menos agressivos, mais versáteis e dotados de um maior controle operacional como as câmaras que são objeto desta discussão.

\section{PARTE EXPERIMENTAL}

\section{Construção das câmaras}

No sistema de envelhecimento acelerado desenvolvido são utilizadas duas câmaras idênticas e independentes para acondicionamento do material em estudo. Cada uma delas, obtidas a partir de moldes retangulares de aço $(30 \times 15 \times 20 \mathrm{~cm})$ fechados com as bases removíveis plásticas, uma superior e outra inferior (Figura 1), recebe de um microcomputador valores de referência de T e UR mantendo, através de um dispositivo de controle, as condições desejadas para o experimento. As câmaras são dotadas também de fonte de radiação luminosa e de sistema para o controle da atmosfera no seu interior, além de circuito eletrônico, interface e software que permitem o acompanhamento e registro das variáveis.

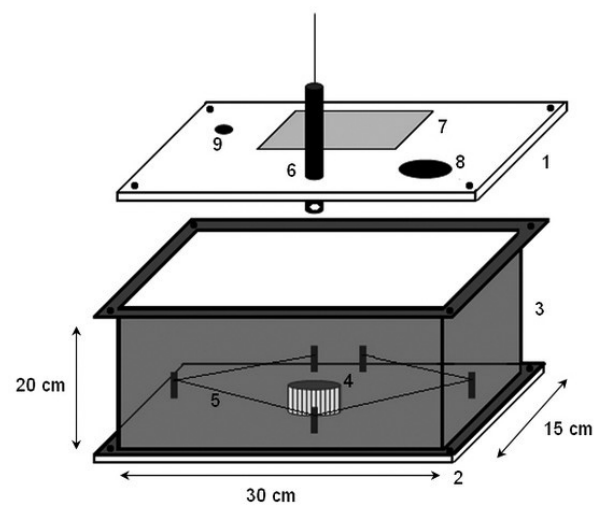

Figura 1. Representação das câmaras de envelhecimento acelerado. 1: chapa de PTFE superior; 2: chapa de PTFE inferior; 3: estrutura de aço inox; 4: ventoinha; 5: resistência interna; 6: sensor de Te UR de altura ajustável; 7: janela de vidro ou quartzo; 8: encaixe para o sistema de entrada de ar; 9: encaixe para a válvula de saída de ar

\section{Materiais}

Para a manufatura das câmaras optou-se por aço inox AISI 304 (Acerinox Ltda., São Paulo) para o invólucro e duas bases removíveis em PTFE (Plasttotal Ltda., São Paulo).

A combinação destes dois materiais permite manter uma ótima resistência química nas temperaturas modestas em que o sistema deverá operar, ${ }^{13,14}$ ao mesmo tempo em que proporciona uma boa troca térmica com o meio externo pelas paredes metálicas e a possibilidade de introduzir modificações nas partes plásticas para a instalação de todos os acessórios necessários. Em particular, para a confecção final das câmaras, é necessário dotar estas caixas de uma janela de vidro borossilicato (ou quartzo, intercambiáveis, ambos com inércia química e resistência térmica elevadas) para a entrada da radiação luminosa gerada por uma fonte apropriada; de um sensor de tempe- ratura e de umidade relativa; de um sistema de aquecimento, ou seja, um enrolamento metálico comercial de níquel-cromo de $60 \Omega(0,5$ mm de espessura) e uma ventoinha; de canais para a introdução de ar, eventualmente enriquecido por gases de interesse; e, opcionalmente, de sensores de tais gases.

Para estes acessórios, foi essencial priorizar materiais que também não fossem sujeitos ao desprendimento de espécies voláteis, inclusive para o encapsulamento de dispositivos (como sensores) adquiridos já prontos e, portanto, sobre os quais não havia controle nos materiais de manufatura.

Entre o bloco de aço e as bases de PTFE utilizam-se vedações de $4 \mathrm{~mm}$ de espessura, preparadas sob medida a partir de silicone comercial bi-componente pré-polimerizado (Sylgard ${ }^{\circledR} 184$ Silicone, Dow Corning Corporation), moldado em fase líquida numa forma retangular perfeitamente plana, polimerizado durante 7 dias e recortado. De acordo com as especificações do fabricante, esse silicone apresenta uma excelente estabilidade térmica na faixa de temperatura entre -45 e $200{ }^{\circ} \mathrm{C}^{15}$ e boa inércia ao ataque de $\mathrm{O}_{3}$.

\section{Controle da temperatura}

O sistema foi planejado para funcionar em uma sala mantida a uma temperatura de cerca de 2 a $3{ }^{\circ} \mathrm{C}$ abaixo da menor temperatura de funcionamento das câmaras, que é de $25^{\circ} \mathrm{C}$. Dessa forma, a termostatização no interior das caixas pode ser mantida no nível desejado através de pulsos de calor gerados pela resistência instalada na base das câmaras e alimentada por uma tensão de $110 \mathrm{~V}$. O contato elétrico se dá por meio de pinos de aço que transpassam a base de PTFE e servem, ao mesmo tempo, de suporte para a resistência aquecedora, posicionada a cerca de $2 \mathrm{~cm}$ do fundo da caixa, conforme mostrado na Figura 1.

A ampla área de aço das câmaras $\left(0,18 \mathrm{~m}^{2}\right)$ permite dissipar rapidamente para o exterior o excesso de calor e impedir o aumento da temperatura acima do valor imposto pelo operador. A manutenção de um regime térmico constante é possível pela quantidade e intensidade dos pulsos de aquecimento, controlada por hardware com base nas leituras de temperatura fornecidas constantemente por um sensor colocado em cada câmara e conectado a um microcomputador.

Uma ventoinha colocada no centro da base inferior e alimentada por uma fonte de $5 \mathrm{~V}$ possibilita uniformizar a temperatura dentro das câmaras. As amostras deverão ser colocadas em suportes, também de material inerte, da altura de aproximadamente $7,5 \mathrm{~cm}$, eventualmente vazados no meio para permitir o livre movimento do ar e, portanto, evitar significativos gradientes de temperatura e composição do ar na câmara.

O dispositivo foi planejado para possibilitar a opção de funcionamento em ciclos térmicos, ou seja, entre níveis diferentes de temperatura por intervalos de tempo pré-definidos, uma função também controlada por software. As especificações dos componentes foram definidas para que a faixa operacional de temperatura seja de 25 a $50{ }^{\circ} \mathrm{C}$, com duração mínima de cerca de 1 h por ciclo.

\section{Controle da composição atmosférica}

As câmaras foram projetadas para trabalharem sob fluxo constante de ar de modo a favorecer o controle da composição da atmosfera, inclusive purgando eventuais produtos gasosos formados durante os processos de envelhecimento artificial. $\mathrm{O}$ ar entra por um orifício inicialmente dentro de uma pré-câmara de acondicionamento, passa em seguida para a câmara principal e, finalmente, é expelido por uma saída dotada de uma válvula anti-retorno.

$\mathrm{O}$ ar utilizado pode ser sintético ou natural; no primeiro caso utiliza-se um cilindro comercial e no segundo, um compressor de ar. 
Para esta finalidade, compressores oil-free para uso odontológico são uma boa opção: além de silenciosos, são desenvolvidos para trabalhar por longos períodos de tempo, têm boa durabilidade e requerem pouca manutenção. Aqui se utilizou um dispositivo 2000-M25 (Jun-Air, Dinamarca) acoplado a um gerador de gás de purga (FTIR Purge Gás Generator, mod. 75-52, Whatman, EUA) para remoção da umidade e purificação do ar.

Para o controle da composição atmosférica, o ar de alimentação preliminarmente purificado e seco deve ser ajustado quanto ao conteúdo de umidade e, eventualmente, enriquecido de algum gás de interesse para o processo de envelhecimento acelerado. $\mathrm{O}$ processo de purificação pode, alternativamente, ser realizado mediante a passagem por colunas preenchidas por carvão ativado e secante; outras substâncias, dependendo do tipo de aplicação, podem também ser usadas. $\mathrm{O}$ enriquecimento por um gás adicional deve ser feito no ar seco e pode quase sempre ser implementado mediante tubos de permeação. Estes são pequenas cápsulas contendo substância pura (sólida ou líquida) em equilíbrio químico com o gás de interesse, o qual difunde por uma membrana permeável e é emitido para o ambiente em quantidade definida pela temperatura; uma das vantagens dos tubos de permeação é que a quantidade exata de gás liberado durante certo tempo pode ser exatamente deduzida por diferença de massa. Assim, o sistema prevê a passagem de ar seco por um alojamento mantido em um banho termostatizado de água onde poderá ser inserido um tubo de permeação (por exemplo, $\mathrm{SO}_{2}, \mathrm{NO}_{2}, \mathrm{H}_{2} \mathrm{~S}$, $\mathrm{NH}_{3}, \mathrm{HCOOH}, \mathrm{CH}_{3} \mathrm{COOH}$ e até mesmo $\mathrm{Hg}$ ).

O controle da umidade relativa do sistema é uma exigência importante em vários tipos de aplicações e isso vale inclusive no estudo do comportamento de materiais usados em bens culturais. Na câmara construída, o controle de umidade relativa ocorre por mistura de dois fluxos de ar, um seco e outro praticamente saturado com vapor de água (Figura 2). Esta segunda linha é formada como derivação da linha de alimentação principal e nela a umidificação se dá por arraste do vapor de água em equilíbrio com água desionizada $(230 \mathrm{~mL})$ mantida a uma temperatura de $40{ }^{\circ} \mathrm{C}$ por uma manta térmica num balão de fundo redondo de $250 \mathrm{~mL}$. A linha úmida, normalmente fechada por um sistema de válvulas solenoide de duas vias, é dotada de uma coluna de condensação de $107 \mathrm{~cm}$ e de um dreno que recebe o excesso de água carregado pelo fluxo de ar e que condensa ao longo da tubulação.

A proporção ar seco/ar úmido na alimentação de entrada na câmara define a umidade dentro dela e é controlada pela abertura pulsada das válvulas solenoide, por sua vez acionadas por hardware, o qual compara a cada momento o nível de umidade relativa medida pelo sensor instalado dentro da câmara com o valor de referência definido pelo operador no software, controlando o acionamento das válvulas. A completa mistura dos dois fluxos de ar ocorre em uma pré-câmara de acondicionamento, inserida dentro da câmara principal e com a qual está em equilíbrio térmico, a fim de evitar fenômenos de condensação da água na câmara principal.

\section{Controle do fluxo luminoso}

As amostras são expostas à radiação luminosa (tanto VIS quanto UV) gerada por uma fonte externa. O fluxo luminoso alcança o interior do sistema através de janelas apropriadas e intercambiáveis de vidro borossilicato ou quartzo $(10 \mathrm{x} 15 \mathrm{~cm})$, instaladas em um alojamento recortado na base superior das câmaras, também dotado de sistema de vedação ao ar. O eventual calor gerado pela lâmpada pode ser trocado por meio de uma ventoinha acoplada que, porém, não impede que a superfície irradiada sofra aumento de temperatura caso a fonte emita uma quantidade não desprezível de radiação infravermelha - uma ocorrência que neste sistema pode ser monitorada por um sensor adicional de temperatura colocado na superfície exposta à luz.

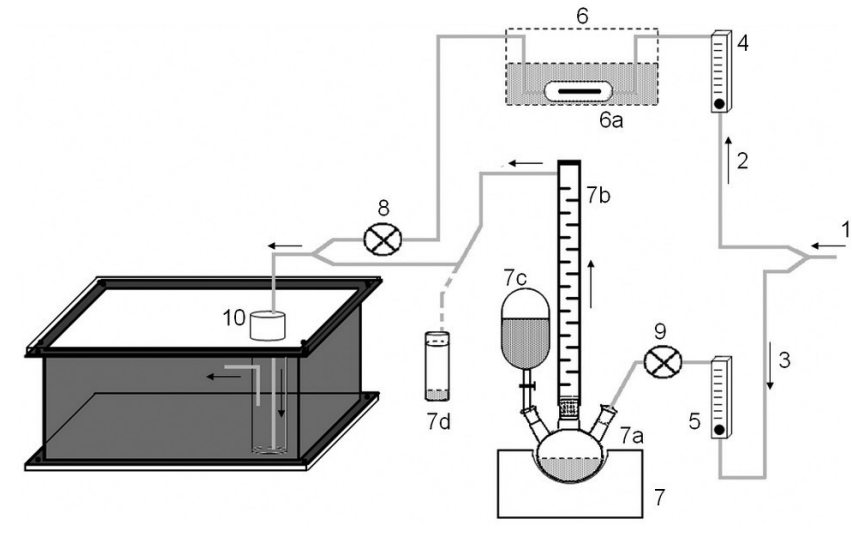

Figura 2. Sistema de alimentação de ar das câmaras. 1: entrada de ar seco e purificado; 2: linha de ar seco; 3: linha de ar úmido; 4: rotâmetro da linha de ar seco; 5: rotâmetro da linha de ar úmido; 6: dispositivo termostatizado para enriquecimento de gases; 6a: alojamento dos tubos de permeação; 7 : dispositivo de umidificação; 7a: balão de fundo redondo parcialmente preenchido com água desionisada e mantido a $40^{\circ} \mathrm{C}$ por uma manta térmica; $7 \mathrm{~b}$ : condensador; $7 c$ : reservatório de água para reposição; $7 d$ : dreno de água de condensação; 8: válvula solenoide de duas vias para a linha de ar seco; 9: válvula solenoide de duas vias para a linha de ar úmido; 10: pré-câmara de acondicionamento do ar

Evidentemente, o tipo e a intensidade da radiação recebida pelas amostras dependem do tipo de lâmpada e das características da janela. Tradicionalmente, sistemas de envelhecimento acelerado utilizam lâmpadas de xenônio, cujo espectro de emissão é o que melhor reproduz aquele da radiação solar que chega à superfície terrestre. No entanto, essas fontes são bastante custosas e produzem uma quantidade de calor considerável, impondo a instalação de um robusto sistema de resfriamento. Mais recentemente, vários autores têm sugerido o uso de tubos de fluorescência acoplados com janelas de vidro borossilicato, alegando resultados parecidos com os obtidos com fontes de xenônio. ${ }^{16,17} \mathrm{Na}$ literatura, geralmente indica-se 315 $\mathrm{nm}$ como o comprimento de onda de corte para a radiação incidente, salientando como, invariavelmente, fontes que emitem abaixo deste limite induzem alterações químicas essencialmente diferentes daquelas registradas em processos de degradação naturais. Um interessante recurso para auxiliar na escolha de lâmpadas de baixo custo para serem utilizadas em envelhecimento acelerado pode ser encontrado num amplo levantamento de espectros de emissão de fontes comerciais de luz disponíveis no mercado brasileiro realizado pelo Centro de Conservação e Restauração de Bens Culturais Móveis da UFMG. ${ }^{18}$

\section{Automação}

A automação do sistema de envelhecimento acelerado tornase essencial tanto pela necessidade de ensaios prolongados e ininterruptos durante os quais o equipamento deve funcionar autonomamente, com um controle preciso dos diversos fatores ambientais, inclusive com a possibilidade da implementação de ciclos entre níveis diferentes de estresse infligido, como pela importância de monitorar e registrar o teor dos fatores ambientais durante a exposição.

Estes objetivos foram atingidos através do controle por parte de um programa escrito em linguagem Delphi ${ }^{\circledR}$ e que se comunica com as câmaras mediante um sistema de interfaceamento, esquematizado na Figura 3 (o esquema eletrônico detalhado pode ser encontrado como Material Suplementar). 


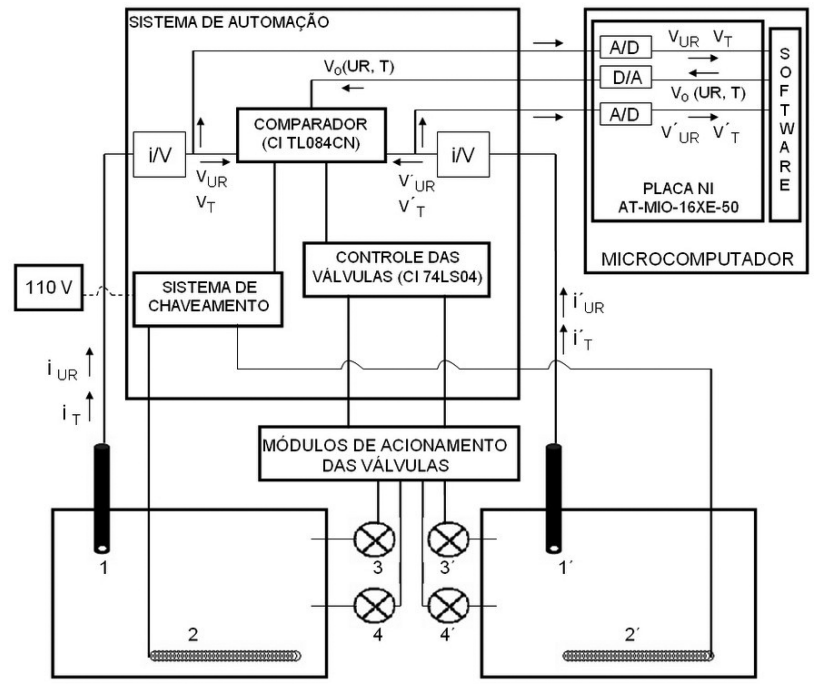

Figura 3. Diagrama esquemático do interfaceamento entre as câmaras e o microcomputador, 1 e 1': sensores de Te UR; 2 e 2': resistências internas; 3 e 3': válvulas solenoide de ar seco; 4 e 4': válvulas solenoides de ar úmido; $i_{U R} e i_{U R}^{\prime}$ correntes associadas aos sinais de UR medidos nas câmaras; $i_{T} e$ $i_{T}^{\prime}$ : correntes associadas aos sinais de T medidos nas câmaras; $V_{U R}$ e $V_{U R}^{\prime}$ : potenciais associados aos sinais de UR medidos nas câmaras; $V_{T} e V_{T}^{\prime}$ : potenciais associados aos sinais de T medidos nas câmaras; $V_{o}(U R, T)$ : potenciais associados aos valores de UR e T definidos para as câmaras pelo software; A/D: conversor analógico-digital; D/A: conversor digital-analógico

A temperatura e a umidade relativa no interior de cada câmara são constantemente monitoradas por um sensor (mod. GTUT, Header Instr. Precisão Ltda., Brasil), posicionado na proximidade do suporte das amostras, que gera correntes (2-20 mA) proporcionais aos valores desses dois parâmetros. Essas correntes são transformadas, através de conversores i/V convencionais baseados em amplificadores operacionais de alto desempenho, em sinais de tensão que são enviados até os conversores A/D de uma placa National Instruments modelo AT-MIO-16XE-50 e armazenados pelo software (uma calibração prévia com este tipo de sensor é necessária). Para o controle de T e UR, os sinais de tensão obtidos são comparados em um circuito integrado TL084CN com valores de referência definidos por software e gerados nas saídas D/A da mesma placa. Até o momento foi empregada uma placa de interfaceamento com apenas duas saídas D/A, o que não possibilita definir valores de Te de UR diferentes nas duas câmaras. No entanto, outros modelos mais recentes e dotados de um maior número de opções (inclusive a conexão via porta USB) estão hoje disponíveis no mercado e podem ser adotados para contornar esta limitação.

Dessa maneira, o comparador sinaliza quando a temperatura cai abaixo do valor definido pelo programa e dispara o sistema de aquecimento, que liga a resistência interna da câmara fornecendo uma corrente proporcional à diferença entre a temperatura definida e a real. $\mathrm{O}$ mesmo princípio de funcionamento foi adotado para o controle da UR, em que o comparador sinaliza quando a UR cai abaixo do valor definido pelo programa, acionando um circuito digital de portas inversoras desenvolvido sobre um circuito integrado 74LS04 que automaticamente definirá níveis lógicos inversos em duas de suas saídas, onde estão conectados módulos eletrônicos de controle das válvulas solenoide. ${ }^{19}$ Desse modo, os sinais do circuito de portas inversoras acionam o módulo que alimenta a válvula de ar úmido e interrompem o funcionamento do módulo que alimenta a válvula de ar seco, permitindo somente a entrada de ar úmido nas câmaras. $\mathrm{O}$ inverso ocorre quando a UR ultrapassa o valor definido no software, sendo acionada a válvula de ar seco e interrompida a válvula de ar úmido, para entrada somente de ar seco nas câmaras.
Apesar deste tipo de lógica ser de fácil implementação por software, a comparação entre o valor de referência e o valor medido e o envio do sinal lógico para gerar a resposta desejada são realizados, num sistema deste tipo, com frequência muito elevada. Um computador convencional pode realizar facilmente esta tarefa, porém o uso simultâneo deste e de outros programas eventualmente acarretaria uma redução na velocidade de atuação do sistema e um aumento na flutuação de UR e T. Ademais, para experimentos de longa duração e realizados sem a supervisão constante de um técnico, como aqueles pretendidos com esta câmara, é interessante que o controle da câmara funcione de forma autônoma, isto é, por hardware, de modo a minimizar os inconvenientes ou riscos de acidentes na eventualidade de o computador ou o software de controle sofrerem alguma interrupção. É muito comum a transferência deste tipo de tarefa para sistemas baseados em amplificadores operacionais, os quais apresentam como atrativo o baixo custo, a facilidade de montagem e uma alta velocidade de operação.

Para evitar a presença de sinais ruidosos e assegurar o funcionamento do sistema, utilizaram-se fontes independentes para a alimentação das partes analógica e digital e os sinais de acionamento do aquecimento são enviados a circuitos integrados TIL111, que proporcionam o isolamento elétrico dos circuitos de baixa e de alta potência.

\section{RESULTADOS}

\section{Funcionamento das câmaras}

As câmaras provaram ser sistemas robustos, capazes de funcionar sem a necessidade de intervenção durante muitos dias, conforme verificado em pelo menos dois estudos completos realizados nos últimos 3 anos. Cabe alertar que, para longos experimentos, o uso de geradores independentes de energia ou de no-break é praticamente imprescindível para evitar indesejáveis interrupções imprevistas na linha de força.

A manutenção da temperatura em valores constantes compreendidos entre 25 e $50{ }^{\circ} \mathrm{C}$ se dá de maneira muito satisfatória, como mostrado na Figura 4A, com flutuações de amplitude típicas de $1{ }^{\circ} \mathrm{C}$ ou ligeiramente maiores a temperaturas mais elevadas. Também a alternância entre dois níveis de temperatura (Figura 4B), foi alcançada com resultados reprodutíveis, ocorrendo em rampas de subida e de descida de 1,5 e 20 min, respectivamente, para mudanças de temperatura entre 25 e $35^{\circ} \mathrm{C}$, ou de 10 a 30 min entre 25 e $50{ }^{\circ} \mathrm{C}$. A vazão do ar injetado mostrou ter certa influência nesses valores de tempo, mas optou-se por não utilizar esse parâmetro como fator de controle, inclusive para evitar aumento de pressão na tubulação de ar. O gráfico apresenta ciclos de duração de 1,5 h a título de exemplificação, mas normalmente se espera trabalhar em períodos mais longos, tipicamente de algumas horas.

O controle da umidade relativa revelou-se menos gerenciável, especialmente quando o sistema trabalha a temperaturas acima de 25 ${ }^{\circ} \mathrm{C}$. Nesse nível térmico, não há problema em fixar e manter a UR da câmara em valores bem definidos entre 25 e $85 \%$, como mostrado na Figura 5A que ilustra como é possível realizar a ciclagem de UR entre teores de 30 e $80 \%$ a $25{ }^{\circ} \mathrm{C}$ em transições bastante rápidas. Já com a câmara aquecida, existem limites na capacidade do sistema de atingir elevados valores de UR, sendo que a Figura 5C indica o patamar máximo alcançável nas diversas temperaturas. Esta limitação se justifica pelo fato de a quantidade absoluta de vapor de água que é preciso ter na câmara para manter o mesmo nível de umidade relativa, a uma temperatura mais elevada, aumenta drasticamente com a temperatura (uma análise de gráficos psicométricos mostra, por exemplo, que quando a temperatura muda de 25 para $35^{\circ} \mathrm{C}$, para manter um nível 

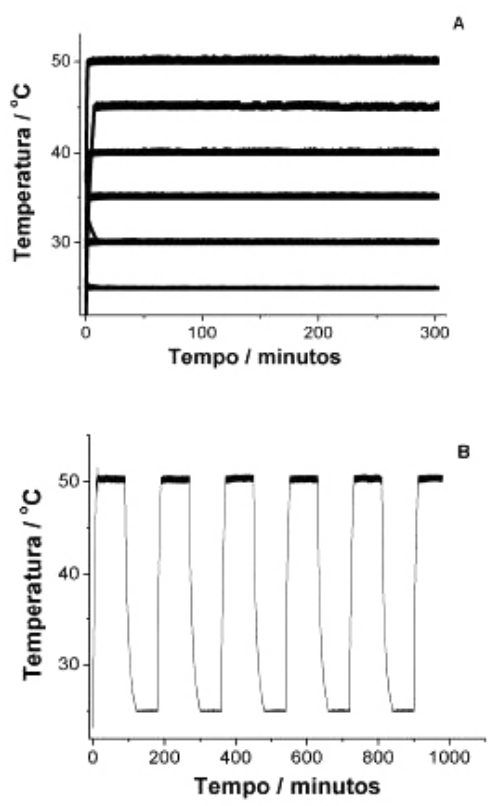

Figura 4. (A) Valores de Tmonitorada na câmara de envelhecimento em regime térmico constante. (B) Valores de T monitorada na câmara de envelhecimento durante ciclos de Tentre as de $25^{\circ} \mathrm{C}(90 \mathrm{~min})$ e de $50^{\circ} \mathrm{C}(90 \mathrm{~min})$

de $60 \%$ de umidade relativa a quantidade absoluta de vapor de água deve aumentar de 2,0 para 3,3 $\mathrm{kPa}$, isto é, deve haver um acréscimo na quantidade de vapor de água de $65 \%$ ). Ademais, para níveis mais elevados de umidade relativa esta variação é mais acentuada, ou seja, fixada a temperatura, é muito mais difícil manter uma umidade relativa elevada do que uma umidade relativa mais modesta.

Uma alternativa bastante prática e utilizada em ensaios em que se requer um controle preciso da umidade relativa baseia-se no uso de sistemas trifásicos, utilizando soluções saturadas de determinados sais. ${ }^{20}$ Estes sistemas, diferentemente daqueles baseados em equilíbrios bifásicos $\mathrm{H}_{2} \mathrm{O}_{2} \mathrm{H}_{2} \mathrm{SO}_{4}$ ou $\mathrm{H}_{2} \mathrm{O} /$ glicerol, não dependem do conteúdo total de água na fase de vapor (umidade absoluta), embora o teor de umidade relativa que eles proporcionam dependa da temperatura. Utilizando, no entanto, sistemas que apresentem baixos coeficientes de temperatura ${ }^{21}$ e na ausência de trocas de ar com a vizinhança, essa solução proporciona uma opção para realizar ensaios a temperatura maiores que $35^{\circ} \mathrm{C}$, alcançando níveis precisos e exatos de UR maiores que $90 \%$. Uma avaliação dos mais apropriados sistemas trifásicos para esta finalidade foi realizada por Greenspan ${ }^{22}$ com base em dados anteriores de Wexler e Hasegawa ${ }^{23}$ e uma síntese destas informações pode também ser encontrada, por exemplo, nos sites de fabricantes de sensores de UR, como o da Omega Engineering Inc. ${ }^{24}$ A Tabela 1 sumariza as possibilidades para criar em um restrito ambiente isolado e mantido a uma temperatura constante escolhida entre 30, 35, 40, e $50{ }^{\circ} \mathrm{C}$ condições de UR constante em 4 faixas principais ao redor dos valores de 50, 70, 80 e $90 \%$.

Para a alternância entre temperaturas distintas é preciso levar em consideração que é possível manter um controle sobre a UR somente dentro de limites definidos, como pode ser observado na Figura 5B na qual é possível ver que para ciclagens entre 25 e $35^{\circ} \mathrm{C}$ o melhor controle sobre a UR se dá em $30 \%$.

A irradiação pode ser realizada em qualquer uma das condições de T e UR identificadas acima, ao passo que o enriquecimento com algum gás agressivo somente é viável, nesse sistema, em condições de UR baixas ou médias, pois a imposição de UR elevadas implica em uma restrição muito significativa na vazão de ar na linha seca, na qual acontece o enriquecimento do ar de alimentação pelo gás.
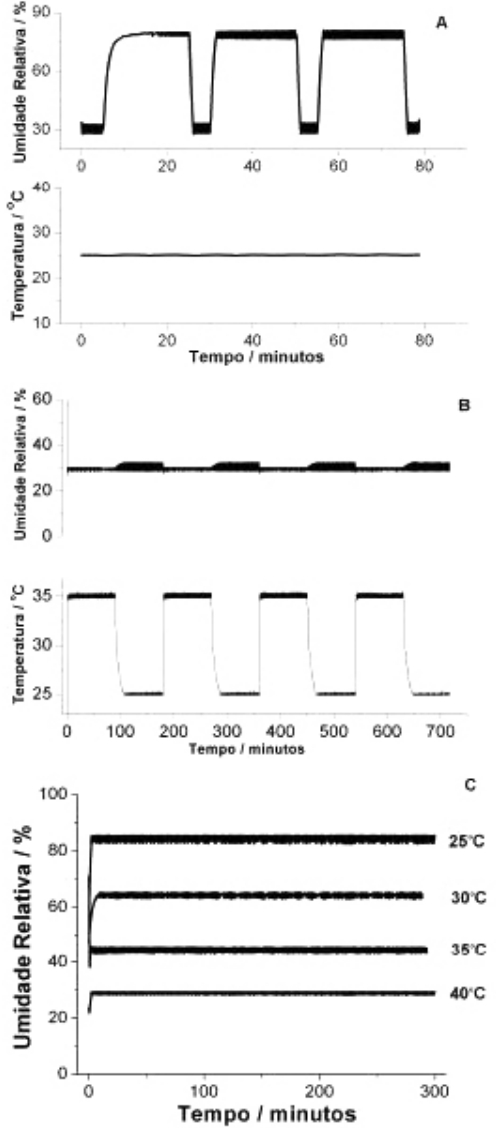

Figura 5. (A) Valores de UR e de T monitoradas na câmara de envelhecimento durante ciclos de UR entre $30 \%$ (5 min) e $80 \%$ (20 min) a $25^{\circ} \mathrm{C}$; (B) Valores de UR e de T monitorados na câmara de envelhecimento durante ciclos de $T$ entre $25^{\circ} \mathrm{C}(90 \mathrm{~min})$ e $35^{\circ} \mathrm{C}(90 \mathrm{~min})$. (C) Valores máximos de UR alcançáveis na câmara de envelhecimento nas $\mathrm{T}$ de $25,30,35$ e $40^{\circ} \mathrm{C}$

Tabela 1. Valores teóricos de UR na fase gasosa nos diversos sistemas trifásicos sal-solução-vapor em equilíbrio nas diferentes temperaturas, adaptada da ref. 22

\begin{tabular}{lcccccc}
\hline $\begin{array}{l}\text { Faixa de UR } \\
\text { desejada }\end{array}$ & $\begin{array}{c}\text { Sais } \\
\text { usados }\end{array}$ & \multicolumn{5}{c}{ Valores teóricos de UR (\%) } \\
\hline $45-50 \%$ & $\mathrm{Mg}\left(\mathrm{NO}_{3}\right)_{2} \mathrm{C}$ & $355^{\circ} \mathrm{C}$ & $40{ }^{\circ} \mathrm{C}$ & $45{ }^{\circ} \mathrm{C}$ & $50{ }^{\circ} \mathrm{C}$ \\
$70-75 \%$ & $\mathrm{NaCl}$ & 75,09 & 74,87 & 78,42 & 46,93 & 45,44 \\
$80-85 \%$ & $\mathrm{KCl}$ & 83,62 & 82,95 & 82,32 & 81,74 & 81,20 \\
$85-95 \%$ & $\mathrm{KNO}_{3}$ & 92,31 & 90,79 & 89,03 & 87,03 & 84,78 \\
\hline
\end{tabular}

A Tabela 2 apresenta um resumo das possíveis condições experimentais proporcionadas pelo sistema descrito. Futuramente, serão realizadas modificações no software e no sistema de automação para a implantação de um contador que marque o tempo total em que houve o enriquecimento da atmosfera da câmara com algum gás.

\section{CONCLUSÕES}

Neste artigo foram apresentados o projeto, construção, desempenho e limitações de uma câmara de envelhecimento acelerado, concebida com a finalidade de investigar o efeito de microambientes sobre processos de degradação de bens culturais. Nela, podem ser controlados de forma independente os quatro fatores ambientais 
Tabela 2. Resumo das condições operacionais aplicáveis às câmaras de envelhecimento acelerado em termos de temperatura, umidade relativa e uso ou não de agentes agressores em fase gasosa (AG). OK: condições viáveis; X: condições não viáveis na atual configuração do sistema

\begin{tabular}{lcccccc}
\hline & \multicolumn{2}{c}{$25^{\circ} \mathrm{C}$} & \multicolumn{2}{c}{$35^{\circ} \mathrm{C}$} & \multicolumn{2}{c}{$50^{\circ} \mathrm{C}$} \\
UR & AG sim & AG não & AG sim & AG não & AG sim & AG não \\
\hline $25 \%$ & OK & OK & OK & OK & OK & OK \\
$50 \%$ & OK & OK & OK & OK & X & X \\
$75 \%$ & X & OK & X & X & X & X \\
\hline
\end{tabular}

preponderantes nesses processos, isto é, iluminação, temperatura, umidade relativa e composição da atmosfera.

Mostrou-se que a câmara construída é muito mais adequada aos estudos sobre bens culturais do que as comerciais disponíveis no mercado; além disso, estimativas mostram que cada câmara tem custo equivalente a cerca de $25 \%$ do valor de uma câmara comercial sendo, também, sob esse ponto de vista uma opção bastante atrativa.

As possibilidades de aprimoramento do projeto são bastante amplas e algumas delas já foram citadas ao longo do texto. Além delas, merecem destaque o aperfeiçoamento do software utilizado, incluindo as possibilidades de operação remota e transferência de dados sem fio. Naturalmente, a implementação desses recursos também implica em uma atualização de itens como interface e processador. Várias dessas modificações já estão sendo consideradas.

\section{MATERIAL SUPLEMENTAR}

O diagrama detalhado representando o circuito eletrônico elaborado e construído para o controle automático de temperatura e umidade relativa das câmaras está disponível gratuitamente em http:// quimicanova.sbq.org.br, na forma de arquivo PDF.

\section{AGRADECIMENTOS}

À FAPESP (projetos de auxilio à pesquisa 01/09497-8, 03/07315$5,03 / 11167-1$ e 06/61437-3), ao CNPq e à Comissão Européia ( $6^{\text {th }}$ Framework Programme, contract N.022695) pelo apoio financeiro e aos alunos e professores do Grupo de Pesquisa em Química Analítica Instrumental do IQ-USP por disponibilizar gentilmente a infra-estrutura.

\section{REFERÊNCIAS}

1. Thomson, G.; The Museum Environment, $2^{\text {nd }}$ ed., Butterwirth-Heinemann: Oxford, 1986.

2. Graedel, T. E.; McGill, R.; Environ. Sci. Technol. 1986, $20,1093$.

3. Brimblecombe, P.; Atmos. Environ. 1990, 24B, 1.

4. van den Brink, O.; Eijkel, G. B.; Boon, J. J.; Thermochim. Acta 2000, $365,1$.

5. Mills, J. S.; White, R.; The Organic Chemistry of Museum Objects, Butterworth/Heinemann: Oxford, 1994.

6. Feller, R. L.; Accelerated Aging: Photochemical and Thermal Aspects, Edwards Bros.: Ann Arbor, 1994.

7. Baer, N. S.; Banks, P. N.; Int. J. Museum Management Curatorship $1985,4,9$.

8. Odlyha, M.; Boon, J. J.; van den Brink, O.; Bacci, M.; J. Therm. Anal. Calorim. 1997, 49, 1571.

9. Bacci, M.; Picollo, M.; Porcinai, S.; Radicati, B.; Environ. Sci. Technol. 2000, 34, 2859.

10. Cavicchioli, A.; de Faria, D. L. A.; Sens. Actuators B 2006, 115, 656.

11. Cavicchioli, A.; de Faria, D. L. A.; Neves, C. A.; Antunes, M. T.; Sens. Actuators B 2008, 131, 462.

12. Bacci, M.; Cucci, C.; Mencaglia, A. A.; Mignani, A. G.; Sensors 2008, 8, 1984.

13. Perry, R. H.; Green, D. W.; Maloney, J. O.; Perry's Chemical Engineers' Handbook, $7^{\text {th }}$ ed., McGraw-Hill: New York, 1997.

14 .Seymour, R. B.; Engineering Polymer Sourcebook, $1^{\text {st }}$ ed.; McGrawHill: New York, 1990.

15. http://www.dowcorning.com/applications/search/default. aspx?R=131EN, acessada em Novembro 2009.

16. van der Doelen, G. A.; PhD Thesis, University of Amsterdam, The Netherlands, 1999.

17. van der Goelen, G. A.; Boon, J. J.; J. Photochem. Photobiol. A 2000, $134,45$.

18. Barreto, L.; Dissertação de Mestrado, Universidade Federal de Minas Gerais, Brasil, 2003.

19. da Silva, J. A. F.; Lago, C. L.; Quim. Nova 2002, 25, 842.

20. Morillon, V.; Debeaufort, F.; Jose, J.; Tharrault, J. F.; Capelle, M.; Blond, G.; Voilley, A.; Fluid Phase Equilib. 1999, 155, 297.

21. Rockland, L. B.; Anal. Chem. 1960, 32, 1375.

22. Greenspan, L.; J. Res. Nat. Bureau of Standards 1977, 81, 89.

23. Wexler, A.; Hasegawa, S.; J. Res. Nat. Bureau of Standards 1954, 53, 19.

24. http://www.omega.com/temperature/z/pdf/z103.pdf, acessada em Novembro 2009. 


\section{CÂMARAS CLIMÁTICAS PARA O ENVELHECIMENTO ACELERADO: AÇÃO DE MICROAMBIENTES SOBRE} BENS CULTURAIS

Renato Inhasz Paiva, José Roberto Caetano da Rocha e Andrea Cavicchioli*

Escola de Artes, Ciências e Humanidades, Universidade de São Paulo, Av. Arlindo Bettio, 1000, 03828-000 São Paulo - SP, Brasil

Fernando Silva Lopes e Dalva Lúcia Araújo de Faria

Instituto de Química, Universidade de São Paulo, Av. Prof. Lineu Prestes, 748, 05508-000 São Paulo - SP, Brasil

É apresentado o diagrama detalhado representando o circuito eletrônico elaborado e construído para o controle automático de temperatura e umidade relativa das câmaras, ilustrado de forma esquemática na Figura 3 do artigo (o circuito apresentado corresponde apenas a uma câmara, sendo que a segunda utilizaria uma placa idêntica). Ele utiliza amplificadores operacionais (AOs) do tipo OPA453T como conversores i/V e AOs do tipo TL084CN como comparadores. O acionamento da placa de controle das válvulas é realizado através de um CI 74LS04 (conforme descrito na Ref. 19) e para o aquecimento um TRIAC (BT139) é acionado por um circuito baseado no CI TIL111 que permite o desacoplamento elétrico entre o circuito de baixa potência e a seção de alta potência. Para redução de ruídos optou-se pela adoção de fontes independentes para a parte digital e analógica. Com relação à placa original usada para a obtenção dos resultados discutidos no artigo, a ilustração apresenta uma versão que foi aprimorada mediante modificações elaboradas durante a redação do manuscrito. 


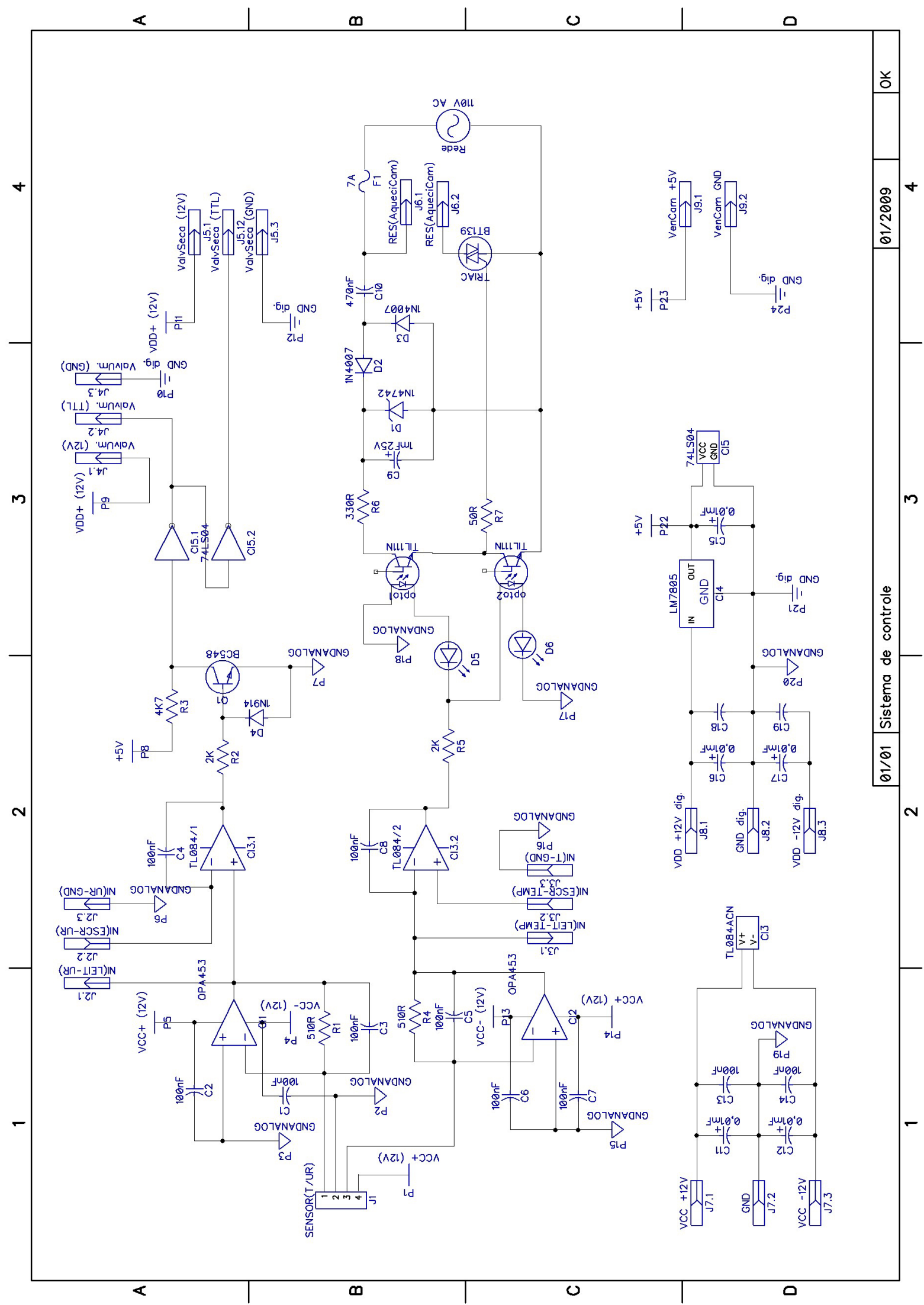

